\title{
La paradoja de la independencia de México
}

Jaime E. Rodriguez O.*

UNIVERSITY OF CALIFORNIA

\begin{abstract}
Revisión historiográfica que da cuenta de los principales trabajos sobre la independencia de México y, a través de ellos, de los principales problemas del periodo.
\end{abstract}

$\mathrm{U}$ no de los problemas más difíciles de explicar dentro de la historia de América es el porqué una antigua colonia, Estados Unidos, logró alcanzar un gobierno estable y desarrollarse económicamente, mientras que las demás-los países latinoamericanostuvieron que sufrir el caos político y el declinar de su economía durante el siglo $\mathrm{XIX}$. La mayoría de los estudiosos vincula los conflictos políticos, económicos y sociales que se dieron en la América española después de la independencia a una herencia colonial de signo negativo.

- Agradezco a Virgina Guedea la cuidadosa traducción de este ensayo. Una primera versión de éste se publicó en el libro Independence, 1989.
Por otra parte, sostienen que la experiencia colonial de Estados Unidos los preparó para autogobernarse. ${ }^{1}$ Así, mientras que la Unión norteamericana se desarrolló rápidamente después de su independencia, la mayoría de las naciones latinoamericanas tuvo que luchar para superar esa "herencia colonial".

México es un caso especial en Latinoamérica. Históricamente ha sido la nación más extensa, rica y populosa de la región. Actualmente, sólo Brasil y Argentina son más grandes. Las culturas precolombinas de México no sólo fueron más

\footnotetext{
' Hartz, Funding, 1964.

2 Véase, por ejemplo, Flores Caballero, Contrarrevoluciōn, 1969.
} 
variadas y numerosas, también fueron más avanzadas que otras comunidades indígenas del continente. Durante el periodo colonial, el virreinato de la Nueva España desarrolló una sociedad más rica y compleja que el resto de la América española. En muchos aspectos, el virreinato del norte funcionó como una metrópoli del imperio español en el nuevo mundo. De hecho, para el sigloxviI la Nueva España con su próspera economía y estructura social compleja, parecía competir con la madre patria. Además, México ha evolucionado de manera un tanto aislada respecto al resto de Latinoamérica. Por todas estas razones, México bien puede ser comparado con Estados Unidos.

Colin MacLachlan y yo hemos argumentado que la experiencia colonial de México no fue del todo negativa. Por el contrario, la Nueva España constituyó la sólida base sobre la cual se fincó el desarrollo de la nueva nación. ${ }^{3}$ También he afirmado que el "fracaso" de México para desarrollarse debe ser estudiado a la luz de lo que he llamado "la crisis mexicana del siglo XIX". De acuerdo con esta perspectiva, la lucha por la independencia đañó tan severamente las estructuras del virreinato que el México republicano sufrió varios tropiezos en su carrera por alcanzar el desarrollo nacional durante el siglo XIX. ${ }^{4}$

Cualquier comparación entre Estados Unidos y México debe también tomar en cuenta los recursos naturales de ambos países. El contraste en este aspecto es sorprendente. Estados Unidos posee extensas y fértiles tierras cultivables, mientras que las regiones agrícolas de México constituyen solamente alrededor de 15\%

${ }^{3}$ MacLachlan y Rodriguez, Forging, 1990.

${ }^{4}$ Rodriguez, Colonialism, 1983. de su territorio. Así, México es pobre en el recurso más importante que el hombre conoce: la tierra cultivable. El contraste topográfico es también sorprendente. Aunque montañas y desiertos representaron un obstáculo para la integración nacional de Estados Unidos, fueron relativamente fáciles de superar y además se localizan en regiones periféricas a la que constituyó el núcleo de la nación durante sus primeros años. Por el contrario, la región central de México se encuentra dominada por masivas cadenas montañosas, grandes desiertos, profundos cañones y extensas selvas que han presentado barreras formidables a la unidad nacional. Mientras que los magníficos sistemas fluviales del este de Estados Unidos unificaron al joven país y facilitaron su desarrollo, ${ }^{5}$ México ha carecido de ríos navegables; por lo tanto es una tierra relativamente pobre, a pesar de su riqueza mineral, y que se ha caracterizado por tener un medio ambiente difícil. Así, la destrucción causada por las guerras de independencia afectaría a México en forma más severa y haría más difícil la recuperación, aun cuando todos los otros factores hubieran sido semejantes.

La índole y el proceso de las luchas por la independencia fueron tan diferentes en ambos países como lo son sus condiciones materiales. La guerra por la independencia de Estados Unidos se convirtió en un conflicto internacional en el que Francia y España, dos de las naciones más poderosas de Europa, lucharon contra Inglaterra por tierra y por mar. En el momento más agudo del conflicto, Francia tenía en Norteamérica una

\footnotetext{
3 Para la geografia de Estados Unidos véase Glassborow y Freman (comps.), Atlas, 1986. El mejor trabajo sobre la geografía mexicana es el de Tamayo, Geografia, 1969. Véasetambién Bataillon, Regiones, 1969.
} 


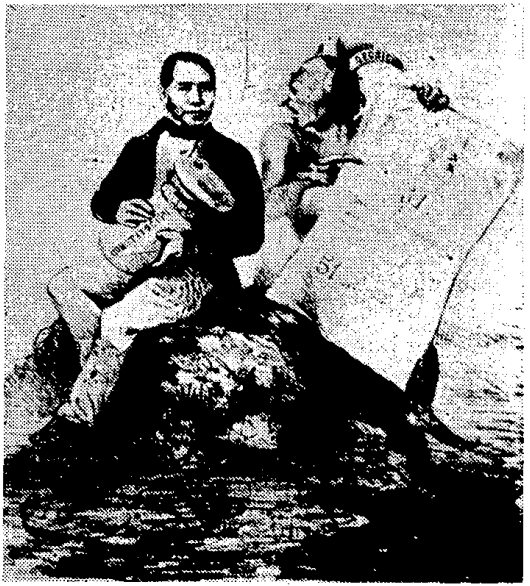

fuerza de más de 10000 hombres, o sea un ejército comparable en tamaño a las tropas realistas de la Nueva España mientras que los soldados españoles molestaban a los ingleses a lo largo de la vasta frontera con Estados Unidos. Al mismo tiempo, las fuerzas navales de España y de Francia neutralizaban la flota inglesa en el mar. Como resultado de esa intervención extranjera, Estados Unidos obtuvo su independencia mediante un acuerdo internacional: el Tratado de Paris de $1783 .{ }^{6}$

A lo largo de la lucha por la independencia, las clases alta y media norteamericanas compartieron objetivos moderados. Los fundadores de la nueva nación, como George Washington, Thomas Jefferson y John Adams, eran miembros de la oligarquía. Representaban la riqueza y el poder en la nueva nación. Ninguna revolución social amenazaba sus intere-

${ }^{6}$ La lucha por la independencia de Estados Unidos es analizada en Alden, American, 1954; Higgenbotham, War, 1972; Smelser, Winning, 1972; Wallace Appeal, 1964. ses. La guerra de independencia de Estados Unidos se caracterizó por acciones militares tradicionales. Fue notable la ausencia de insurgentes con objetivos del todo diferentes a los de la elite, y ciertamente no se dio una insurrección rural. Los esclavos negros no se rebelaron contra sus amos, los indios no aprovecharon la oportunidad para recuperar las tierras de que habían sido despojados. ${ }^{7}$

Aunque existian tensiones regionales y aunque la primera constitución de Estados Unidos, los Artículos de la Confederación, fue rápidamente descartada en favor de una constitución más fuerte, la de 1787 , la elite norteamericana se las arregló para dirigir a la nueva nación sin que se le presentaran serios retos de otros grupos sociales. Esto, en gran medida, fue el resultado de la prosperidad del periodo posterior a la independencia originada por 20 años de guerra europea. La revolución francesa de 1789 y las guerras que la siguieron, crearon en Europa una demanda insaciable de productos estadunidenses. Así, las tensiones que existían en la nueva nación se vieron aligeradas por la prosperidad del país. ${ }^{8}$

Las guerras de la independencia mexicana fueron muy distintas a la experiencia de Estados Unidos. La lucha en la Nueva España se caracterizó por una falta de consenso entre la elite, por insurrecciones rurales de masas, por conflic-

${ }^{7}$ Los historiadores de Estados Unidos no han tendido a considerar la lucha por la independencia comounmovimientosocial. El trabajo de Jamenson, American, 1929, resulta útil todavía. Véanse también Jensen, American, 1975 y Green, "Social", 1973.

${ }^{8}$ El desarrollo económico de la joven república es hábilmente analizado en Bruchey, Roots, 1965. También resultan útiles para entender el desarrollo inicial de Estados Unidos los trabajos de Jensen, Articles, 1959 y Nation, 1950, así como el de Miller, Federalist, 1960.

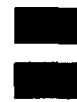


tos raciales y de clase y por el surgimiento del regionalismo. Las clases altas y medias -los españoles americanos- se vieron superadas por una pequeña minoría de españoles europeos. Después de casi dos décadas de continuas y gravosas demandas para sostener la guerra en Europa, la corona española sufrió un colapso en mayo de 1808 , a consecuencia de la invasión de la península por Napoleón. En la ciudad de México los españoles europeos, temerosos de la elite nacida en América, derrocaron al gobierno virreinal el 16 de septiembre de 1808 . A partir de entonces una pequeña minoría de españoles europeos dominó la Nueva España. La elite nacida en América, los criollos, obviamente se sintió molesta bajo un régimen que consideraba ilegal y anticonstitucional. Se multiplicaron las conspiraciones para alcanzar la autonomía y una de ellas desató accidentalmente una guerra de castas y de clases cuando el 16 de septiembre de 1810 el cura Miguel Hidalgo incitó a las masas a seguirlo. ${ }^{9}$ Así, dos movimientos distintos -una lucha urbana por la autonomía y una lucha rural contra la explotaciónparecieron fundirse en la gran insurrección de Hidalgo, pero, mientras las masas rurales se vengaban de sus antiguos opresores, ya fueran españoles europeos o americanos, la elite de Nueva España se vio obligada a posponer su lucha por la autonomía mientras buscaba sobrevivir a esta nueva, inesperada y peligrosa insurgencia rural.

Al contrario de lo ocurrido en Estados Unidos, la elite novohispana perdió el

\footnotetext{
${ }^{9}$ Guedea, "Criollos", 1964; Villoro, Proceso, 1981, pp. 41-63; Ladd, Mexican, 1976, pp. 89-94, 106-115; Hamill, "Discurso", 1979, pp. 439-474 e Hidalgo, 1966; Alamán, Historia, 1985. Esta última obra es aún la mejor narración, y la más detallada, sobre el periodo.
}

control del movimiento en favor de la autonomía ante una insurrección rural apoyada en las masas. Durante meses, decenas de miles de insurgentes rurales desolaron el Bajío y Jalisco, dos de las regiones novohispanas más productivas. Cuando el ejército realista derrotó al movimiento de Hidalgo en marzo de 1811, el cura José María Morelos y sus seguidores continuaron la lucha. A pesar de que España envió tropas experimentadas para sofocar la rebelión, la insurgencia se fragmentó rápidamente y se extendió a varias de las regiones más prósperas del virreinato. A esto siguió una lucha masiva prolongada y encarnizada en extremo.$^{10}$ Cuando terminó, en 1821, casi la décima parte de la población había muerto, la economía estaba destrozada y la legitimidad de sus instituciones destruida. ${ }^{11}$ La década de la insurgencia, los años que van de 1810 a 1821 , había preparado el escenario para la inestabilidad política, el estancamiento económico y los conflictos sociales del periodo posindependiente.

Debido a que la insurgencia mexicana incluía varios intereses en conflicto, la elite de Nueva España se dividió. Algunos de sus miembros favorecieron a determinados insurgentes, mientras que otros creyeron que el movimiento liberal español podría brindarles un poco de autonomía. Otros más, temerosos de los conflictos de clase y de castas desatados por la insurgencia, apoyaron el restablecimiento del antiguo orden y el regreso

\footnotetext{
${ }^{20}$ El mejor trabajo sobre Hidalgo es el de Hamill, Hidalgo, 1966. Para el movimiento de Morelos véanse Guedea, Morelos, 1981; Lemoine, Revolución, s.f.; Alamán, Historia, 1985; Archer, "Royalist", 1981, pp. 57-83 y "Where", 1989, pp. 24-43, es quien ha estudiado más ampliamente al ejército español.

"Hamill, "Was", 1976, pp. 43-61; Tutino, Insurrection, 1986, pp. 41-212; Hamnett, Roots, 1986.
} 
del monarca. A causa de estas divisiones, la elite novohispana no pudo formar un grupo integrado que pudiera haber obtenido el apoyo de las potencias extranjeras. ${ }^{12} \mathrm{~A}$ diferencia de Estados Unidos, los insurgentes novohispanos no gozaron de la ayuda de ejércitos y fuerzas navales extranjeras. En lugar de esto, algunos aventureros entraron en la Nueva España en busca de riquezas y gloria. De hecho, varios filibusteros procedentes de la república del norte intentaron desmembrar al país. ${ }^{13}$

La lucha por la independencia novohispana tampoco concluyó con un arreglo internacional. España primero y posteriormente la Santa Alianza continuaron amenazando a la nueva nación después de 1821. México, a diferencia de Estados Unidos, tuvo que asignar la mayor parte de su presupuesto a la defensa del país durante su primera década como nación independiente. Cuando en septiembre de 1821 Iturbide tomó posesión del nuevo gobierno, encontró muy pocas simpatías fuera de México. Es verdad que Estados Unidos reconoció a la nueva nación en 1822 y, lo que fue más importante, la Gran Bretaña le dio su reconocimiento en diciembre de 1824 , sin embargo, estas acciones significaron tan sólo una parcial aceptación internacional de México. A pesar de la supuesta doctrina Monroe, el apoyo de Estados Unidos a la nueva nación fue un tanto tibio y, aunque la Gran Bretaña se opuso a los intentos de otros países europeos, en especial los de la Santa Alianza, por destruir la republica mexicana, no se opuso a los intentos de España por reconquistar su antigua colonia. Como resultado de ello,

${ }^{12}$ Ladd, Mexican, pp. 112-131; Anna, Fall, 1978, pp. 35-190.

${ }_{13}$ Warren, Sword, 1943; Guedea, "Beginning", 1988.
España no reconoció la independencia de México sino hasta 1836. Francia había extendido su reconocimiento tan sólo unos cuantos años antes, en 1832. ${ }^{14}$

México alcanzó su independencia en 1821 , después de terminadas las guerras europeas. La nueva nación no sólo tuvo que reconstruir su destrozada economía, también tuvo que enfrentarse a la falta de demanda de sus productos. Además, Europa y Estados Unidos se hallaban ansiosos de inundar México con sus propias mercancías. Por ello, México no gozó de la prosperidad de que disfrutó Estados Unidos durante sus primeros años. En vez de esto, el Estado mexicano tuvo que hacer frente a graves problemas, tanto internos como externos, con recursos que fueron cada vez menores. ${ }^{15}$

A pesar de que las condiciones internacionales eran adversas a la nueva nación mexicana, fue la guerra de independencia la que afectó profundamente su desarrollo. Los once años de lucha fueron un periodo crítico. La insurgencia y la contrainsurgencia no sólo minaron las viejas estructuras sociales, políticas y económicas, en muchos casos las destruyeron al tiempo que creaban nuevos intereses y nuevos antagonismos. Los conflictos se volvieron especialmente violentos después de que el ejército realista derrotara las insurrecciones de Hidalgo y de Morelos y la insurgencia se fragmentara en varias y violentas guerras de guerrillas. La amarga lucha entre las numerosas partidas de insurgentes y las recién llegadas fuerzas expedicionarias españolas puso fin al antiguo orden colonial, e hizo imposible la reconciliación con España.

${ }_{14}$ Rodriguez, Emergence, 1985, pp. 59-67, 85178, 229-234; Bosch Garcia, Problemas, 1986.

15 Tenenbaum, Politics, 1986, pp. 1-40. 
La insurgencia tan prolongada causó nuevos y graves problemas a la joven nación. Como han sostenido Virginia Guedea y Christon Archer, las fuerzas de la contrainsurgencia realista militarizaron a la Nueva España. Los oficiales expedicionarios venidos de España aplicaron en el virreinato las lecciones que habían aprendido en carne propia de la contrainsurgencia francesa en la península. Hicieron a un lado a las autoridades civiles e impusieron la ley marcial para extraer fondos de los gobiernos locales y conseguir reclutas para sus filas. En sus intentos por restaurar el orden y destruir a la insurgencia, los oficiales peninsulares no sólo no tomaron en cuenta las costumbres y las prácticas tradicionales, sino que además actuaron con gran crueldad. ${ }^{16}$ Únicamente si entendemos

16 Virginia Guedea ha estudiado extensamente la insurgencia. Véanse de la autora, "México", 1980, cuán novedosa y desusada para la Nueva España fue la naturaleza de sus acciones, así como la brutalidad tanto de la insurgencia como de la contrainsurgencia, podremos comprender el intenso odio que los mexicanos demostraron a los españoles después de la independencia. La expulsión de los nacidos en España, ocurrida en 1827 y 1829 , no se debió a "antiguos agravios coloniales",

pp. 23-66; "José", 1985, pp. 287-295; "Indios", 1986, pp. 11-83. Sobre la contrainsurgencia véanse los trabajos de Christon 1. Archer, "Royalist", 1981; "Where", 1979; "Officer", 1980, pp. 137-158; "Banditry", 1982, pp. 59-89; "Dineros", 1985, pp. 39-55; "Surviving" (en prensa). Tanto Guedea como Archer sostienen que la militarización de la Nueva España transformó al virreinato y afectó profunda . mente a su población (comunicación personal, México, 26 de junio de 1987). El examen que hice del ramo "Operaciones de guerra" del Archivo General de la Nación me convenció de la certeza de su planteamiento.

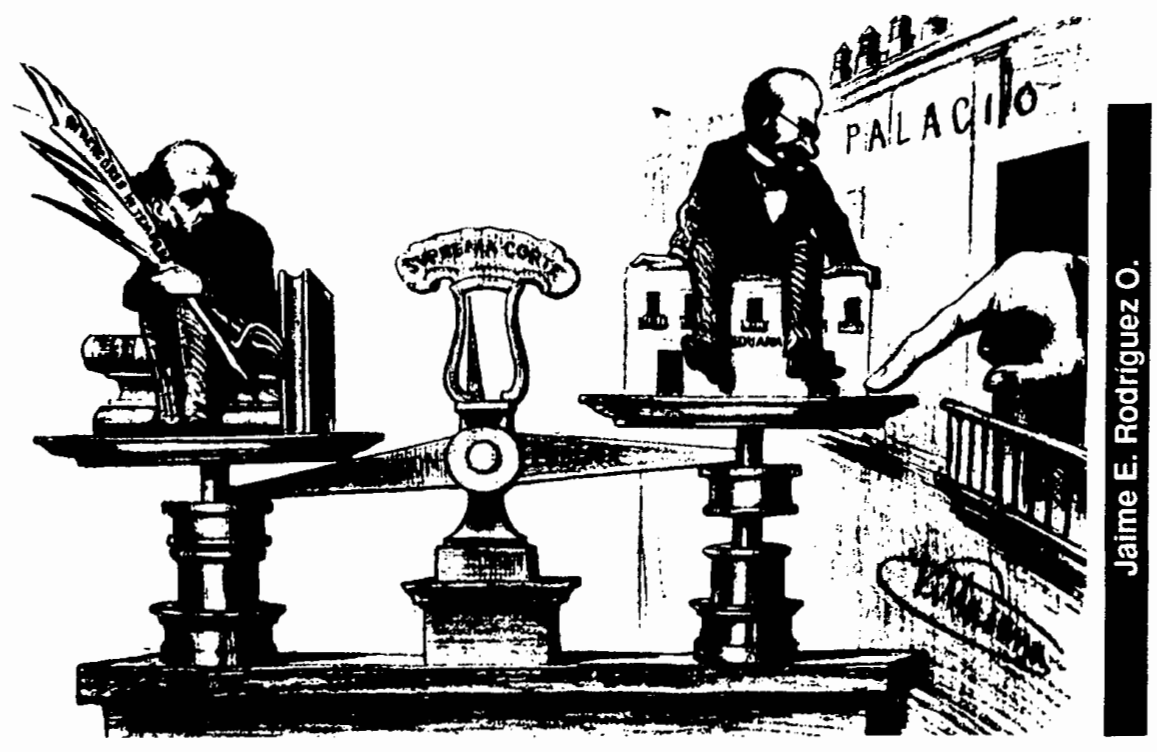


como a menudo se ha afirmado, sino que fue resultado directo de la ferocidad de la contrainsurgencia. ${ }^{17}$

La militarización del virreinato también fomentó el crecimiento del regionalismo. Aunque en la Nueva España los sentimientos regionalistas habían existido desde hacía mucho, no habían llegado a amenazar el orden establecido. La creación de las intendencias a finales del siglo XVIII y el establecimiento de los ayuntamientos constitucionales y de las diputaciones provinciales por las cortes españolas a principios del XIX, fortalecieron aún más los sentimientos locales. El darse cuenta de que el gobierno civil de la capital no podía proteger a las provincias de las depredaciones de los insurgentes, ni tampoco de los excesos de las tropas realistas, convenció a los dirigentes locales de la necesidad de asumir el control de sus zonas. Después de la independencia las elites regionales impusieron a la nación su idea de federalismo con una determinación y una rapidez asombrosas. ${ }^{18}$

La violencia y la destrucción provocadas por la insurgencia dañaron la economía del virreinato. Pero, como John TePaske ha señalado, fueron las continuas y cada vez mayores demandas de dinero para sostener primero la guerra en Europa y después la contrainsurgencia en la Nueva España las que destruyeron las finanzas novohispanas y enajenaron

\footnotetext{
${ }^{17}$ La explicación más satisfactoria de la expulsión de los españoles es la de Flores Caballero, Contrarrewolución, 1969. Sims, Expulsión, 1974; Descolonización, 1982; Reconquista, 1984, proporciona todos los detalles al respecto, pero no vincula el virulento movimiento antiespañol con la represión masiva que se dio durante la contrainsurgencia, como lo sugiere Flores Caballero.

${ }^{18}$ Benson, Dipulación, 1955; Rodríguez, "Intellectuals" (en prensa).
}

a las elites mexicanas, ${ }^{19}$ que después de la independencia no estuvieron dispuestas a financiar al gobierno, y en vez de esto, cifraron sus esperanzas en los préstamos extranjeros y en las rentas de las aduanas. Sin embargo, como Barbara Tenenbaum ha mostrado, estos recursos fueron insuficientes para sostener a los gobiernos posindependientes. ${ }^{20} \mathrm{Así}$ la lucha por la independencia afectó profundamente la manera en que el nuevo país se vio obligado a actuar durante la primera mitad del siglo XIX.

La nueva nación mexicana surgió casi por accidente. Las elites se encontraban profundamente divididas y fueron incapaces de constituir un liderazgo fuerte o unificado. Al igual que las masas urbanas y rurales y que el ejército, las elites se hallaban exhaustas por los once años de guerra. Cuando un oscuro oficial, el coronel Agustin de Iturbide, proclamó el Plan de Iguala que se proponía alcanzar la independencia, todas las facciones se le unieron de inmediato. El régimen español llegó a su término no porque fuera derrotado militarmente, sino porque los mexicanos ya no le brindaron su apoyo político. Sin embargo, el Plan de Iguala no significó más que un respiro momentáneo y no pudo sobrevivir a las tensiones políticas, económicas y sociales que surgieron después de su triunfo. ${ }^{21}$

Los mexicanos recibieron la independencia con gran alegría por todo el país. Aclamaron a Iturbide como a un gran héroe, como a un estadista de amplia visión y como al libertador de México. Sin embargo, su popularidad resultó tan breve como el consenso temporal basa-

\footnotetext{
${ }_{19}$ TePaske, "Financial", 1989, pp. 63-83.

20 Tenenbaum, Politics, 1986, pp. 17-175.

21 Alamán, Historia, 1985, t. v, pp. 50-130; Robertson, Iturbide, 1983; Anna, Fall, 1978, pp. 191209; Ladd, Mexican, 1976, pp. 126-128.
} 
do en el Plan de Iguala y se evaporó después de que se coronara como emperador y que la nueva administración encarara difíciles problemas de índole económica y política. El régimen de Iturbide fue el primero de los gobiernos independientes que se enfrentó a una nueva realidad nacional: pérdida de legitimidad y falta de confianza. Su imperio fracasó al no poder conseguir el apoyo político y económico de la elite. ${ }^{22}$

Los mexicanos establecieron en 1824 una república federal en un intento de restaurar la legitimidad, pero el nuevo régimen se enfrentó a los nismos problemas que el anterior: estancamiento económico, políticas sectarias, regionalismo, amenazas externas y, el más importante de todos, falta de confianza. Terminó en 1835, cuando se estableció una república centralista. Sin embargo, el nuevo gobierno demostró, como los anteriores, ser igualmente incapaz de restaurar la autoridad. Entre 1821 y 1848 tan sólo un presidente, Guadalupe Victoria (182428), terminó su periodo y debió su éxito, sobre todo, a los dos grandes préstamos extranjeros que se negociaron en $1824 \mathrm{y}$ 1825 y que dieron estabilidad financiera a su administración. A lo largo de las dos décadas siguientes, la república pasó por tres constituciones, 20 gobiernos y más de 100 gabinetes. ${ }^{23} \mathrm{El}$ país se hundió en la 79-110

${ }^{22}$ Ocampo, Ideas, 1969; Anna, "Role", 1985, pp.

${ }^{23}$ La historia política del México posindependiente continúa siendo confusa. El trabajo clásico de Alamán, Historia, 1985, resulta un excelente -aunque prejuiciado-relato. Entre los historiadores de la época los mejores son Bustamante, Continuación, 1953-63; Bocanegra, Memorias, 1986-87; Zavala, Ensayo, 1985; Mora, México, 1986. Los mejores trabajos escritos enlos últimos años son los de Robertson, Iturbide, 1983; Flores Caballero, Contramevolución, 1969; Rodriguez, Emergence, 1985; Costeloe, Primera, 1975; Macune, Estado, 1978; Díaz y Díaz, Caudillos, 1972; Tenenbaum, Politics, 1986; Green, Mexican, 1987; González Navaro, Anatomia, 1977. anarquía mientras que las distintas administraciones demostraron ser incapaces de mantener el orden y proteger las vidas y la prosperidad El temor y la incertidumbre se volvieron cotidianos. Antiguos soldados convertidos en bandidos infestaron los caminos, obstaculizando el comercio y amenazando a las poblaciones pequeñas. Éstas y otras manifestaciones de disolución social contribuyeron a la inestabilidad del país. ${ }^{24}$

La situación empeoró cuando el problema político degeneró en guerra civil. Grandes regiones del país se vieron asoladas mientras federalistas y centralistas, liberales y conservadores luchaban por el control político. En la década de 1835 a 1845 los separatistas establecieron las repúblicas de Yucatán y de Texas, aunque sólo esta última logró consolidar su independencia. No obstante, las demás regiones mantuvieron su autonomía del gobierno nacional -aunque no su independencia-por la fuerza de las armas.

La inestabilidad política del país convirtió a México en presa fácil de agresores externos. La república sufrió varias invasiones: de España en 1829, de Francia en 1838, de Estados Unidos en 1847, de Inglaterra, Francia y España en 1861. La desintegración de la nación llevó a muchosindividuos, tanto de dentro como de fuera, a temer que México dejara de existir. Para 1848 el país había perdido más de la mitad de su territorio ante Estados Unidos y la regeneración nacional parecía inalcanzable.

¿Por qué México no se recuperó prontamente, después de su independencia? ¿Por qué se hundió en la depresión económica y en el desorden político durante 50 años? La respuesta parece ser tanto económica como psicológica. La econo-

\footnotetext{
${ }^{24}$ Vanderwood, Disorder, 1981, pp. 25-89.
} 


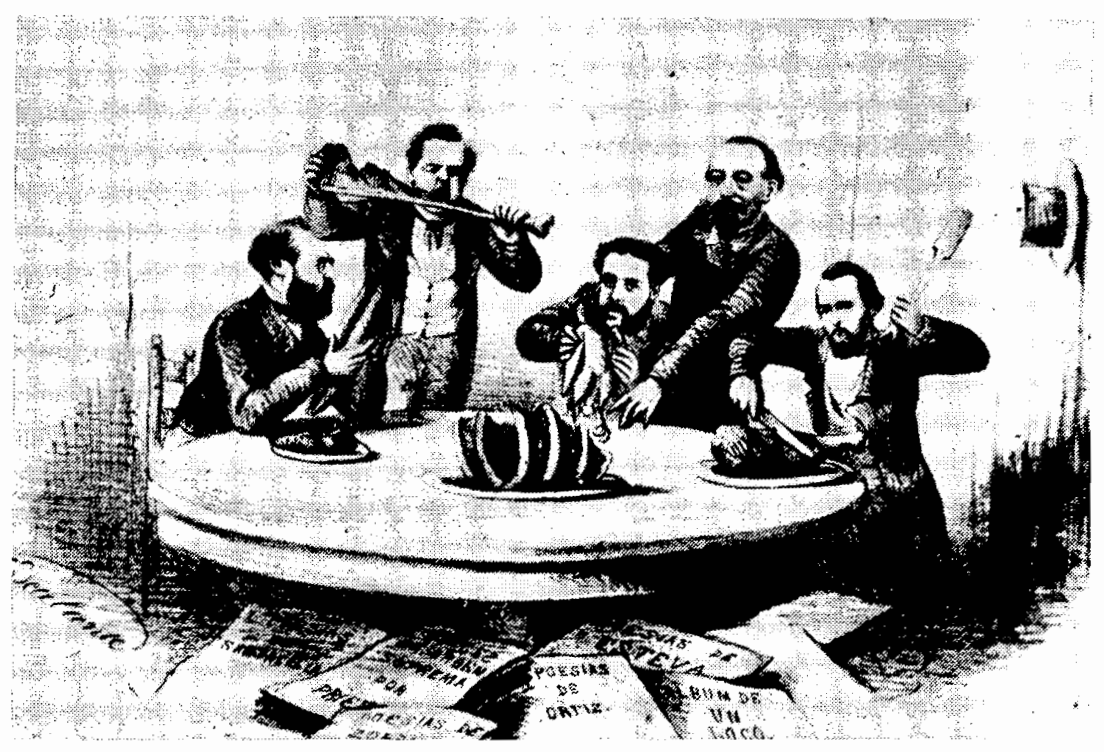

mía mexicana se encontraba en ruinas como resultado del caos político de después de la independencia. Pero, además, los mexicanos dejaron de tener confianza en las instituciones de su país. La legitimidad, ese elusivo acuerdo sobre cuál es la naturaleza del gobierno y de la sociedad, demostró ser difícil de alcanzar. Se necesitaron muchos conflictos, incluyendo la gran guerra civil de 1857 a 1867 , conocida como de Reforma y la intervención francesa, antes de que el país recuperara su sentido de unidad y de propósito. ${ }^{25}$

\section{BIBLIOGRAFÍA}

-Alamán, Lucas, Historia de Méjico desde los primeros movimientos que prepararon su independencia en el año de 1808 basta la época presente, $\mathrm{FCE}$, México, 1985, 5 vols.

${ }^{25}$ Rodríguez, Colonialism, 1983, pp. 15-31.
-Alden, John R., The american revolution, 1775-1783, Hamish Hamilton, Londres, 1954.

-Anna, Timothy E., The fall of the royal government in Mexico city, University of Nebraska, Lincoln, 1978.

,"The role of Agustin de Iturbide: a reappraisal", Journal of Latin America Studies, núm. 17, 1985, pp. 79-110.

-Archer, Criston I., "The officer corps in New Spain: the martial career, 1759-1821", Jabrbuch Fur Geschicbte von Staat, Wirtschaft und Gasellschaft Lateinamerikas", 1980, pp. 137-158.

"The royalist army in New Spain: civilmilitary relationships, 1810-1821", Journal of Latin American Studies", vol. XIII, (1), 1981. "Banditry and revolution in New Spain, 1790-1821", Bibliotheca Americana, núm. 1, noviembre de 1982 , pp. 59-89. , "Los dineros de la insurgencia", en Carlos Herrejón Peredo (comps.), Repaso dela independencia, El Colegiode Michoacán, Zamora, 1985, pp. 39-55.

, Where did all the royalists go? New light on the military collapse of New 
Spain, 1810-1822", en Jaime Rodríguez O., The mexican and mexican american experience in the 19th century, Tempe, 1989.

"Surviving the chaos of insurgency. Urban-rural relationships in Mexico, 1810-1821", en Ricardo A. Sánchez, Eric Van Young y Gisela von Wobeser (comps.), $L a$ ciudad y el campo en la bistoria de México, UNAM, México (en prensa).

-Bataillon Claude, Las regiones geográficas en México, Siglo XXI, México, 1969.

-Benson, Nettie Lee, La diputación provincial y el federalismo mexicano, El Colegio de México, México, 1955.

-Bocanegra, José María, Memorias para la bistoria del México independiente, $\mathrm{FCE}$, México, 1986-1987, 3 vols.

-Bosch García, Carlos, Problemas diplomáticos del México independiente, UNAM, México, 1986.

-Bruchey, Stuart, The roots of american economic growth 1607-1861, Harper and Row, Nueva York, 1965.

-Bustamante, Carlos María de, Continuación del cuadro bistórico de la revolución mexicana, Biblioteca Nacional, México, 19531963, 4 vols.

-Costeloe, Michael P., La primera repüblica federal de México, 1824-1835, FCE, México, 1975.

-Díaz y Díaz, Fernando, Caudillos y caciques, El Colegio de México, México, 1972.

-Flores Caballero, Romeo, La contrarrevolución en la independencia: los españoles en la vida política, social y económica de México, 1808-1838, El Colegio de México, México, 1969.

-Glassborow, Gilly y Gillian Freman (comps.), The Atlas of the United States, Nueva York, 1986.

-González Navarro, Moisés, Anatomia del poder en México, El Colegio de México, México, 1977.

-Green, Jack P., "The social origins of the american revolution: an evaluation and an interpretation", Political Science Quarterly, núm. 88, 1973, pp. 1-22.

-Green, Stanley C., The mexican republic: the first decade, Pittsburg, 1987.

-Guedea, Virginia, "Criollos y peninsula- res en 1808: dos puntos de vista sobre lo español", tesis de licenciatura, Universidad Iberoamericana, México, 1964.

"México en 1812: control político y bebidas prohibidas", Estudios de bistoria modernay contemporánea de México, vol. viII, 1980, pp. 23-66.

José María Morelos y Pavón: cronología, UNAM-IIH, México, 1981.

"José Nemesio Vázquez, un correo insurgente", en Antonio Pompa y Pompa yotros, Dela bistoria bomenaje a Jorge Gurria Lacroix, UNAM, México, 1985, pp. 287-295.

"Los indios voluntarios de Fernando VII", Estudios de bistoria moderna $y$ contemporánea de México, 1986, vol. x, pp. 11-83.

"The beginning of relations between Mexico and the United States", ponencia presentada en la Semana Mexicana, Universidad de Calgary, Calgary, 21-26 de marzo de 1988.

-Hamill Jr., Hugh M., The Hidalgo nevolt: prelude to mexican independence, University of Florida Press, Gainsville, 1966.

, "Was the mexican independence movement a revolution?", en Fomento Cultural Banamex, Dos revoluciones: México y los Estados Unidos, Banamex, México, 1976. "Un discurso formado con angustia: Francisco Primo de Verdad el 9 de agostode 1808", Historia Mexicana, vol. XXVIII (3), enero-marzo de 1979, pp. 439-474.

-Hamnett, Brian R., Roots of insungency: mexican regions, 1750-1824, Cambridge University Press, Cambridge, 1986.

-Hartz, Louis, The funding of new societies, Brace and World, Nueva York, 1964.

-Higgenbotham, Don, The war of american independence, Nueva York, 1972.

-Jamenson, James Franklin, The american revolution considered as a social movement, Princeton, 1929.

-Jensen, Merrill, The new nation, Vintage Books, Nueva York, 1950.

Madison, 1959, 2a. ed.

$$
\text { The articles of confederation, }
$$

Nueva York, 1975.

The american witbin America,

-Ladd, Doris M., The mexican nobility at 
independence, 1780-1826, University of Texas at Austin, Austin, 1976.

-Lemoine, Ernesto, La república federal mexicana. La revolución de independencia: 1808-1821, México, s.f., t. III.

-MacLachlan, Colin M. y Jaime E. Rodríguez 0. The forging of the cosmic race: $A$ reinterpretation of colonial Mexico, University of California, Berkeley, 1990, 2a. ed.

-Macune, Charles, El Estado de México y la federación mexicana, FCE, México, 1978.

-Miller, John C., The federalist era, 17891800, Harper and Brothers Publishers, Nueva York, 1960.

-Mora, José María, México y sus revoluciones, FCE, México, 1986, 3 vols.

-Ocampo, Javier, Las ideas de un día, El Colegio de México, México, 1969.

-Robertson, William S., Iturbide of Mexico, Duke University Press, Durham, 1983.

-Rodríguez O., Jaime E. (comp.), The independence of Mexico and the creation of the new nation, University of California, Los Ángeles, 1989.

Down from colonialism Mexico's nineteenth century crisis, University of California, Los Ángeles, 1983.

"Intellectuals and the Constitution of 1824", en Roderic Ai Camp, Charles A. Hale and Josefina $Z$. Vázquez, The State and intellectual life in Mexico. Los Ángeles-México (en prensa).
America: Vicente Rocafuerte and spanish americanism, 1808-1832, University of $\mathrm{Ca}$ lifornia, Berkeley, 1985.

-Sims, Harold D., La expulsión de los españoles de México, 1821-1830, SEP-FCE, México, 1974.
Descolonización de México: el conflicto entre mexicanos y españoles, 1821 1830, FCE, México, 1982.

La reconquista de México: la bistoria de los atentados españoles, 18211830, FCE, México, 1984.

-Smelser, Marshall, The winning of Independence, Chicago, 1972.

-Tamayo, Jorge L., Geografía general de México, Instituto Mexicano de Investigaciones Económicas, México, 1969, 2a. ed., 4 vols.

-Tenenbaum, Barbara A., The politics of penury: debts and Texas in Mexico, 18211856 , University of New Mexico, Albuquerque, 1986.

-TePaske, John Jay, "The financial desintegration of the royal government during the epoch of independence", en Jaime E. Rodriguez O., Independence, 1989, pp. 6383.

-Tutino, John, From insurrection to revolution in Mexico: social base of agrarian violence, 1750-1940, Princeton University Press, Princeton, 1986.

-Vanderwood, Paul J., Disorder and progress: bandits, police and mexican development, University of Nebraska, Lincoln, 1981.

-Villoro, Luis, El proceso ideológico de la revolución de independencia, UNAM, México, 1981, 3a. ed.

-Wallace, Willard M., Appeal to arms: a military bistory of the american revolution, Chicago, 1964.

-Warren, Harris G., The sword was their passport, Baton Rouge, 1943.

-Zavala, Lorenzo de, Ensayo bistórico de las revoluciones de México desde 1808 basta 1830, FCE, México, 1985. 


\section{SECUENCIA}

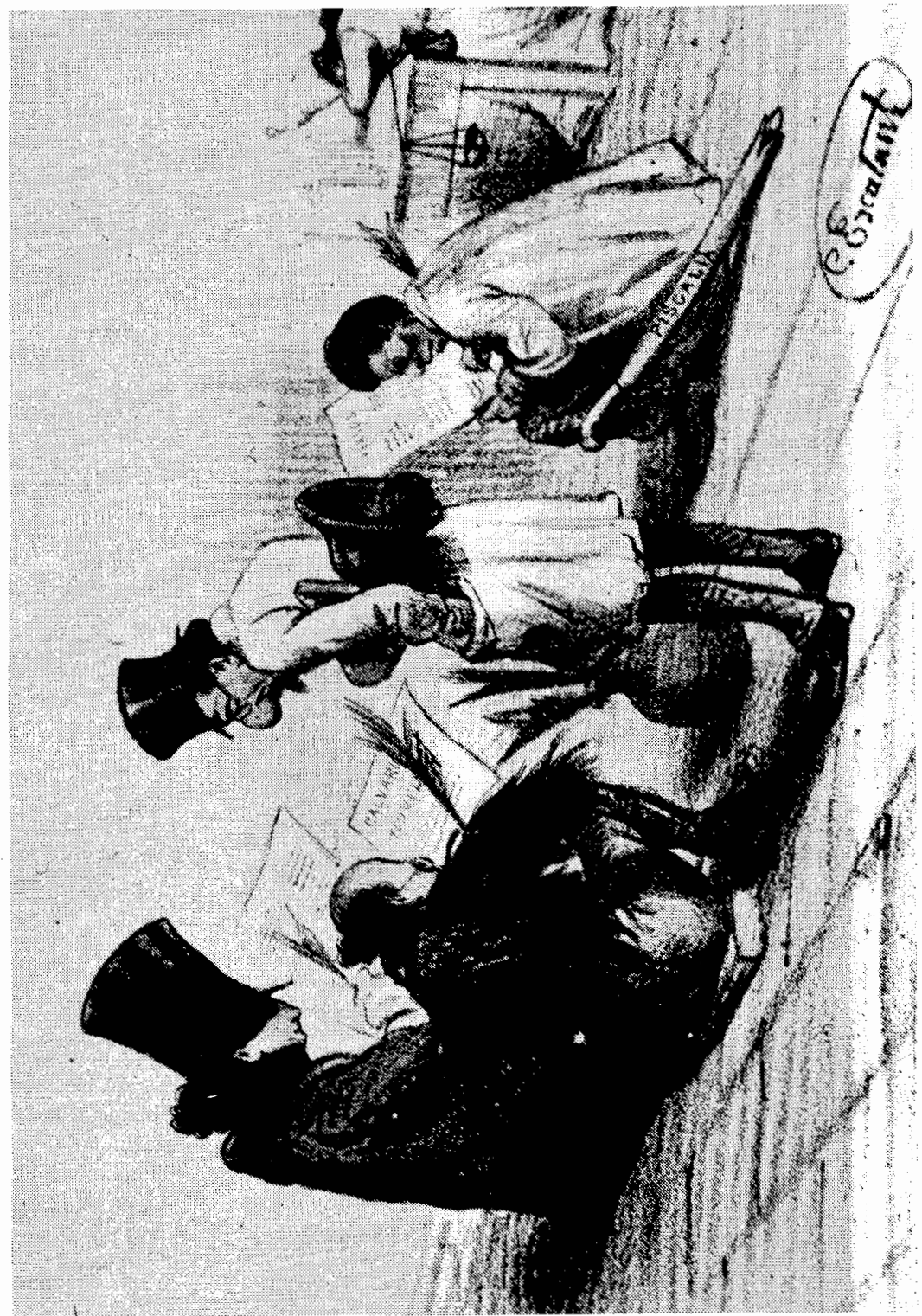

